\title{
ALUNOS DE ESCOLA BÁSICA E SUAS REPRESENTAÇÕES DE PROFESSORES
}

\author{
PRIMARY EDUCATION STUDENTS AND THEIR REPRESENTATIONS \\ OF TEACHERS
}

\author{
Roberta Kolling Escalante \\ Rosely Perez Xavier**
}

\begin{abstract}
Resumo
Este artigo analisa como alunos de escola básica representam socialmente o professor em aspectos como gênero, idade, aparência, atitude e metodologia de ensino. Também examina os efeitos desses aspectos na relação aluno-professor. A pesquisa baseou-se na Teoria das Representações Sociais (MOSCOVICl, 1978, 1984, 2004) e contou com a participação de 69 estudantes de diferentes fases escolares, que foram submetidos a um questionário e a uma entrevista em grupo focal. Os dados mostraram que certos estereótipos são percebidos nas representações dos alunos sobre os professores e que aspectos como a atitude e a metodologia de ensino podem gerar conflitos na relação aluno-professor.

Palavras-chave: Representações Sociais. Professores de escola básica. Interação professor-aluno.
\end{abstract}

\begin{abstract}
The present paper analyses how primary education students represent teachers in aspects such as genre, age, appearance, attitude, and teaching methodology. It also examines the effect of these aspects on the student-teacher interaction. The study was based on the Social Representation Theory (MOSCOVICl, 1978, 1984, 2004), and it included 69 students from different school levels who were asked to answer a questionnaire as well as interview questions in focus groups. In addition to revealing some stereotypes in the representations of students about teachers, the data showed that teachers' attitudes and their methodology may create tensions in the classroom.
\end{abstract}

Keywords: Social representations. Primary education teachers. Teacher student interaction.

\section{Introdução}

Na organização da sociedade as características sociais de um indivíduo costumam representá-lo. Elas dão expressão a padrões ideais na representação. Isso acontece, por exemplo, na representação de certas profissões. Os advogados são vistos, em geral, como sujeitos que se vestem de maneira formal (terno e gravata), possuem aparência discreta e utilizam uma linguagem com expressões marcadas da área de atuação.

Mesmo sendo voláteis, dinâmicas e presentes em diversos contextos, as representações se constroem e se fortalecem principalmente no ambiente educacional por ser um local de desenvolvimento e inculcação do conhecimento, de ideias, valores e atitudes, de internalização de hábitos e normas, para professores e alunos.

As representações do trabalho docente, nas perspectivas social e educacional, encontram-se

Professora da Universidade Federal da Fronteira Sul (UFFS). E-mail: rokolesc@gmail.com

* Professora associada da Universidade Federal de Santa Catarina (UFSC). E-mail: rosely@ced.ufsc.br muitas vezes vinculadas não só à formação profissional do exercício da docência, mas também aos aspectos como idade, gênero, aparência física, linguagem e modo de agir dos professores. Por essa razão, a profissão docente, enquanto objeto de pesquisa, transcende o saber e o fazer pedagógico, envolvendo também características pessoais inerentes, que podem eventualmente afetar a relação professor-aluno.

Por representações nos referimos às projeções sociais, muitas vezes idealizadas a partir da disseminação de ideias e de percepções advindas do senso comum. As representações refletem as condições consensuais e contextuais dos sujeitos que as elaboram e são orientadas por um conjunto de antecipações e expectativas sobre um indivíduo e/ou objeto.

No campo escolar, as representações que os alunos carregam e constroem sobre o professor podem entrever relações mais ou menos harmoniosas, dependendo da imagem que o professor projeta nos alunos através de sua aparência física, gênero, idade, atitude e metodologia de ensinar. Esses elementos, dependendo de como se configuram, podem influenciar a relação aluno - professor. 
Tendo como finalidade analisar as representações sociais construídas por alunos de escola básica sobre os professores em geral, partimos das seguintes perguntas de investigação: como os fatores gênero, idade, aparência física, atitude e metodologia de ensinar dos professores influenciam as representações dos alunos sobre esses profissionais? Que implicações esses fatores podem ter na interação/ relação do aluno com o professor?

Este estudo parte do referencial teórico-metodológico da Teoria das Representações Sociais (MOSCOVICI, 1978, 1981, 1984, 2004) e do entendimento de que as percepções e os conceitos que orientam os indivíduos no contexto escolar contribuem para a compreensão das condutas assumidas pelos sujeitos envolvidos na interação pedagógica.

\section{Sobre a Teoria das Representações Sociais (TRS)}

O estudo clássico que originou a Teoria das Representações Sociais foi La psycanalyse, son image et son public (1961), realizado pelo psicólogo social romeno radicado na França Serge Moscovici, no final da década de 50 . Seu objetivo era compreender como a teoria psicanalítica se disseminava de forma diferente nos diversos grupos sociais da cidade de Paris. $O$ estudo foi motivado pela necessidade que o autor sentia em redefinir o campo de estudo da Psicologia Social, tendo como ponto de partida o fenômeno das representações sociais.

Apoiado nos fundadores das Ciências Sociais na França, principalmente em Durkheim, da Sociologia, e em Lévi-Bruhl, da Antropologia, Moscovici defendia a inexistência do sujeito fora de um contexto social. O contato com o pensamento de Durkheim permitiu a Moscovici transpor a barreira tradicional entre fenômenos psíquicos e sociais, enquanto que a visão antropológica de Lévi-Bruhl permitiu-lhe realizar, através da Psicologia Social, o "casamento entre a Psicologia e a Antropologia" (MOSCOVICI, 1978).

Ao questionar o conceito cartesiano de razão como atributo imutável e universal do ser humano, Lévi-Bruhl provocou uma mudança no que se acreditava até então: seres humanos são sujeitos racionais, sem dúvida, mas de maneira relativa e incompleta, dependentes da cultura à qual pertencem (MOSCOVICI, 1978 apud GUARESCHI; JOVCHELOVITC, 2002). Na visão de Lévi-Bruhl, cada cultura tem sua própria lógica interna. Consequentemente, representações coletivas podem ser racionais para os membros de uma determinada cultura, mas descabidas e privadas de sentido para os membros de outra.
Partindo de uma perspectiva crítica sobre representações coletivas na Sociologia de Durkheim e na Antropologia de Lévi-Brhul, Moscovici elaborou sua Teoria das Representações Sociais, agregando também as contribuições de Piaget e Vigotsky.

Segundo Moscovici (2004), a TRS se apóia na psicologia genética de Piaget, que estudou o senso comum das crianças, da mesma forma que Moscovici buscava estudar o senso comum dos adultos. Com base nos métodos utilizados por Piaget para estudar crianças (i.e. observações e entrevistas focais), Moscovici percebeu que a mesma metodologia poderia servir-Ihe nas pesquisas em representações sociais.

A Psicologia do Desenvolvimento de Piaget estava interessada na transformação das representações espontâneas em representações científicas e racionais no curso da vida da criança. Ao considerar que os organismos vivos podem adaptar-se geneticamente a um novo meio, Piaget defendia a existência de uma relação evolutiva entre o sujeito e o seu meio. Nessa relação, a criança constrói e reconstrói suas ações e ideias quando se relaciona com novas experiências ambientais, em que o cognitivo está em supremacia em relação ao social e o afetivo.

$\mathrm{Na}$ visão de Piaget, a criança elabora o conhecimento social como um ser humano singular, mediante a sua elaboração cognitiva, através do mecanismo de acomodação e assimilação, como base da evolução de um estado de equilíbrio a outro, por meio da organização de elementos preexistentes.

Moscovici (2004) salientou que Piaget teria se aproximado das proposições de Durkheim ao entender que as representações coletivas implicam uma continuidade de conceitos e de formas de pensamento singulares, formando assim uma "consciência coletiva".

Quanto à contribuição de Vigotsky para a TRS, Moscovici (2004, p. 299) explicou que "a partir dos escritos de Vigotsky, a origem das funções mentais mais elevadas deve ser buscada não nas profundezas da mente ou nos tecidos nervosos, mas na história social, fora do organismo individual".

Ao introduzir juntamente com Alexander Luria a dimensão histórica e cultural na psicologia, Vigotsky formulou uma teoria do desenvolvimento cultural humano. Para ele, os processos mentais superiores nos seres humanos são profundamente influenciados pelos meios sócio-culturais que os mediam. Vigotsky e Luria foram os primeiros a planejar um estudo de campo, em escala relativamente ampla, sobre as representações dos Uzbeks na Ásia Central no início da década de 30 do século $X X$, uma população vinculada a sua religião $e$ ainda vivendo de modo tradicional, mas que passava 
por transformações no plano social e cultural, como consequência da revolução.

Segundo Moscovici (2004, p. 297), Vigotsky teria seguido Levy-Bruhl na hipótese da descontinuidade das representações ao criticar a ideia de que a humanidade partilha de uma homogeneidade psíquica, pois, segundo Vigotsky, há uma tensão mental em toda cultura. Logo, uma mesma cultura pode gerar distintas representações, sem estabelecer as mesmas categorias da mente humana para todas as culturas em todos os tempos.

Em seu estudo conduzido em 1961, Moscovici substituiu a noção de representações coletivas pelo conceito de representações sociais na justificativa da diversidade da origem, tanto dos indivíduos quanto dos grupos. Ele reconheceu a importância da comunicação enquanto fenômeno que possibilita convergir os indivíduos numa rede de interações em que tanto o indivíduo se constitui socialmente, como a sociedade se constitui na individualidade dos sujeitos, dando forma ao aspecto mutável da sociedade. A construção da Teoria das Representações Sociais baseia-se, portanto, na indissociabilidade entre o indivíduo e a sociedade, abrindo espaço para a interlocução entre a Psicologia e a Sociologia.

A noção de representações sociais, introduzida na Psicologia Social por Moscovici, emerge da compreensão sobre como o saber é representado na sociedade e compartilhado entre os seus membros na forma de teorias do senso comum. Nas palavras de Moscovici (1981, p. 181), representações sociais são:

[...] um conjunto de conceitos, enunciados e explicações originado na vida cotidiana [...] Elas são o equivalente, em nossa sociedade, aos mitos e aos sistemas de crença das sociedades tradicionais; poder-se-ia mesmo considerá-las como a versão contemporânea do senso comum.

Consideradas como "teorias do senso comum", as representações sociais se estruturam na comunicação (MOSCOVICI, 1978) e podem ser expressas através dos discursos das ciências, das religiões e de outras tantas formas de conhecimento compartilhado. Assim sendo, todos os fenômenos que emergem do contexto social são investidos simbolicamente, ou seja, recebem nomes e significados que os avaliam, explicam e Ihes dão sentido. Esses significados circulam e se modificam de acordo com os modelos vigentes em uma determinada época e formação social. Pode-se assim dizer que as representações sociais são construídas não somente com base no contexto social e cultural, mas também no contexto histórico, o que nos permite novamente associar as contribuições de Vygotsky à TRS.
Um dos pontos fundamentais para o entendimento das representações sociais são as interações humanas. Moscovici (2004) tomou como ponto de partida o aspecto coletivo e social para então discutir a constituição psicológica dos indivíduos, considerando a sua realidade social, histórica e cultural na interação com outros indivíduos. Dessa forma, as representações são construídas e compartilhadas social e historicamente e, quando fortalecidas culturalmente pelo grupo no qual circulam, podem constituir uma realidade social. Aspectos da representação podem, entretanto, modificar-se ao longo dos tempos e desaparecer para o ressurgimento de novos aspectos a serem incorporados na representação.

Dois processos sociocognitivos atuam dialeticamente na formação das representações: a objetivação e a ancoragem. A objetivação é definida como a transformação de uma ideia, conceito ou opinião em algo concreto. Cristaliza-se por processo figurativo e social, passando a constituir o núcleo central de uma determinada representação, frequentemente evocada, concretizada e disseminada como se fosse o real daqueles que a expressam. Consiste em dar forma ao conhecimento de algo ou alguém.

Para Moscovici, objetivar é descobrir a qualidade icônica de uma ideia, é reproduzir um conceito em uma imagem. Em outras palavras, "a imagem é totalmente assimilada e o que é percebido toma lugar do que é concebido [...] Assim, por uma espécie de imperativo lógico, as imagens se tornam elementos de realidade mais do que elementos de pensamento." (MOSCOVICI, 1984, p. 40).

A ancoragem, por sua vez, refere-se ao processo de integração cognitiva do objeto representado (ideias, acontecimentos, pessoas, relações etc.) com o pensamento social pré-existente. Ancorar é classificar ou denominar um objeto. Sobre a denominação, Moscovici (1984, p. 34) salienta:

Minhas observações provam que denominar uma
pessoa ou coisa é precipitá-la (como uma solução
química é precipitada) e que as conseqüências dis-
so são três: (a) uma vez denominada, a pessoa ou
coisa pode ser descrita e adquire certas caracterís-
ticas, tendências, etc.; (b) ela se torna distinta de
outras pessoas ou coisas através dessas caracte-
rísticas e tendências; (c) ela se torna o objeto de
uma convenção entre aqueles que adotam e parti-
lham a convenção.

Esta classificação acontece quando escolhemos um protótipo estocado em nossa memória, com o qual o objeto representado é posto numa comparação generalizante ou particularizante. Ao fazermos essa comparação, o objeto se inclui ou se afasta de determinada categoria ou classe, a partir da coincidência ou divergência em relação a um único ou poucos aspectos salientes que definem o protótipo (definido pela lógica natural do consenso). 
A TRS explica que a maior parte dos indivíduos aceita e assimila conhecimentos elaborados pela sociedade através das representações do senso comum de distintos grupos sociais. Essas representações são organizadas de maneiras diferentes, segundo sua imbricação em relações sociais diferentes.

Ao terem relacionado estereótipos e representações, Moscovici e Hewstone (1983, p. 119) afirmaram: "Somos levados, por nossas representações, a classificar os fatos diferentemente, e os fatos que não correspondem às representações são considerados como menos reais do que os que a elas correspondem."

As formas de representação e de expressão da sociedade, a partir da TRS, se constituem quando as pessoas se encontram para falar, argumentar, discutir o cotidiano, ou quando estão expostas às instituições (como a escola, por exemplo), aos meios de comunicação, aos mitos e à herança histórico-cultural de suas sociedades.

A fascinação estética está em toda parte e faz da cultura contemporânea uma cultura figurada em que a ênfase nas imagens, mais do que nas palavras, cria novas relações do homem com o desejo e o conhecimento. Segundo Jobim e Souza (2000, p. 16), a presença da imagem e das representações no contexto educativo, "como característica geral da cultura do consumo, penetra todas as instâncias, já que a educação e as práticas sociais que se formam em seu interior começam a ser absorvidas por representações visuais".

No âmbito da educação, as representações sociais constituem "o campo integrador de significação que organiza e orienta o pensamento social e a prática educativa" (MAYA, 2000, p. 29) e "parecem ser fundamentais para se compreender a relação entre os diversos grupos sociais e as suas atitudes e comportamentos face à escola ou, a um nível mais restrito, para se compreender a comunicação na sala de aula" (GILLY, 1989, p. 383). Sua validade e importância no campo educativo é retratada por Gilly (2002, p. 232) a seguir:

O interesse essencial da noção de representação social para a compreensão de fatos da educação é que ela orienta a atenção sobre o papel de conjuntos organizados de significações sociais no processo educativo [...] ela oferece uma nova via para a explicação de mecanismos pelos quais os fatores propriamente sociais agem sobre o processo educativo e influenciam os resultados deles; e da mesma forma, ela favorece as articulações entre psico-sociologia e sociologia da educação.

Dessa forma, considerar o construto das representações sociais em questões educacionais implica entender como os indivíduos, através de suas interações sociais no dia-a-dia da escola, assimilam, veiculam, agem e também constroem os seus próprios conceitos e imagens, os quais orientam sua conduta e comportamento na escola. É nessa perspectiva que a presente pesquisa se insere, buscando entender como as representações dos alunos sobre os professores são influenciadas por fatores como gênero, idade, aparência física, atitude e metodologia de ensinar.

\section{Metodologia da pesquisa}

De natureza exploratória, este estudo contou com a participação de 69 estudantes, distribuídos em três grupos: $5^{a}$ série (20 alunos entre 11 e 14 anos - As 5 doravante), $8^{\mathrm{a}}$ série (16 alunos entre $13 \mathrm{e}$ 15 anos - As8 doravante) e $3^{\circ}$ ano do Ensino Médio (33 alunos entre 16 e 23 anos - As3 doravante). $O$ objetivo foi delinear um panorama das representações que os alunos de diferentes fases de escolarização e maturidade têm sobre os professores em geral.

Na época da coleta de dados, em 2005, os As5 e os As3 estudavam em escola pública, enquanto os As8 cursavam escola particular, ambas situadas na cidade de Florianópolis. Do total de participantes, 55 $\%$ eram do sexo feminino e $45 \%$, do sexo masculino.

As turmas escolhidas foram aquelas que cursavam o espanhol como língua estrangeira, critério que fora estabelecido por se tratar de uma pesquisa que, a princípio, visou a refletir sobre a formação de professores de espanhol atuantes na escola básica. Essa questão, entretanto, é discutida em outro trabalho.

Para Menin e Shimizu (2005, p. 188), "a maioria dos trabalhos em representação social e educação combina mais de um instrumento metodológico. O meio mais utilizado para identificar as representações sociais é a análise de discursos obtidos por meio de entrevistas semi-estruturadas ou questionários". Nesta pesquisa, questionário e entrevista em grupo focal foram instrumentos utilizados para a coleta de dados.

O objetivo do questionário foi conhecer as opiniões dos alunos sobre as imagens que carregam sobre os professores em geral. Consistiu de perguntas fechadas e abertas e uma questão com escala atitudinal Likert, que requer o grau de concordância/ discordância do respondente com relação a determinadas afirmações. Foi uma escala de cinco pontos que consistiu em: 1 Discordo totalmente; 2 Discordo; 3 Tenho dúvidas quanto a isso; 4 Concordo e 5 Concordo plenamente. 
Na elaboração do questionário foi utilizada a técnica de Associação Livre ( $A L)$ como suporte de coleta para o conteúdo das representações sobre os professores. Essa técnica, baseada na produção verbal dos sujeitos (ABRIC, 1994), de caráter espontâneo, menos controlada e aliada a uma dimensão projetiva, permite ao pesquisador chegar aos elementos que constituem o universo semântico do objeto pesquisado, neste caso, o professor.

A partir das respostas dos alunos à associação livre para a palavra professor, foi possível dar tratamento quantitativo aos dados, agrupando-os pela sua frequência de ocorrência, e tratamento qualitativo, ao interpretar e categorizar as palavras citadas.

A análise consistiu em quantificar a palavra mais frequente, relacionando-a com outras que apareciam nos dados e que se vinculavam ao seu campo semântico. Dessa forma, foi possível considerar as perspectivas quantitativa e qualitativa através da análise temático-conteudinal da palavra.

Após a aplicação do questionário, uma entrevista semiestruturada em grupo focal foi conduzida com uma amostra aleatória de cinco a sete alunos de cada turma, com o objetivo de especular sobre as possíveis implicações das representações dos alunos na sua interação/ relação com o professor em geral. Foram, no total, três entrevistas, cada qual com uma amostra aleatória de cada turma, gravadas em áudio, transcritas e submetidas a uma análise interpretativista, visando a compreender os significados/sentidos que os informantes dão às suas proposições e experiências.

Entrevistas em grupo focal visam estimular os participantes a falar e a reagir àquilo que outras pessoas no grupo dizem. Segundo Bauer e Gaskell (2002), o grupo focal é um ambiente mais natural e holístico. "Há uma interação social mais autêntica do que a entrevista em profundidade, [...] os sentidos ou representações que emergem são mais influenciados pela natureza social da interação em vez de se fundamentarem na perspectiva individual." (BAUER; GASKELL, 2002, p. 75).

Oliveira e Werba (2002, p. 112) esclareceram que "não existe uma metodologia exclusiva para a análise das RS, sendo que, encontramos desde investigações realizadas em uma base quantitativa, como as que trabalham com dados qualitativos, e ainda alguns que fazem uso complementar destas duas abordagens". Para este trabalho, os dados foram submetidos a uma descrição percentual e a uma análise qualitativa de cunho interpretativista, na busca de um sentido relacional das identificações e constatações, estabelecendo inferências com base na revisão de literatura.

\section{As representações dos alunos sobre a profissão docente}

A partir da análise das cinco palavras e/ou expressões citadas pelos alunos para o termo professor, foi possível associá-las a categorias como: cenário escolar, afetividade, jeito de ser, aspectos pedagógicos, modelo/exemplo, relação/interação, avaliação, autoridade e aparência, a serem discutidas adiante.

No geral, as palavras frequentemente evocadas foram: "chato(s)" (8,51\%), "legal" e "estudar" (4,5\% cada uma), "aula" (3,6\%), "prova" e "exigente" (3,2\% cada uma). Se analisarmos cada grupo de alunos, a palavra de maior frequência pelos As5 foi "aula" (10,2\%), situando o professor na dimensão pedagógica (de conhecimento e de ensino-aprendizagem). Em seguida, citaram a palavra "escola" $(9 \%)$, sinalizando o cenário escolar como espaço legitimado do professor, onde exerce seu trabalho. Nessa mesma direção, apareceram "sala" $(6,8 \%)$, "quadro" (5,6\%) e "caderno" (4,5\%), que integram o microcosmo do professor e alunos.

A palavra mais proferida pelos As8 e As3 foi "chato(s)" (15,6\% e 9,1\% respectivamente), inserindo o professor na dimensão afetiva (negativa). Se compararmos os As5 com os As8 e As3, podese dizer que, com a experiência escolar, a imagem do professor passa por certo desgaste. Alguns As8 e As3, no entanto, preservaram o professor numa dimensão afetiva positiva, como sinalizado pela segunda palavra mais evocada pelos As8, isto é, "legal" (9,3\%). Essa mesma palavra foi a terceira mais proferida entre os As3 (4,5\%).

O termo professor também está associado à dimensão avaliativa, sugerindo o poder desse profissional em decidir quem é aprovado ou não, como indicado pela segunda palavra mais citada pelos As3, isto é, "prova" (5,2\%).

A categoria cenário escolar contempla elementos que fazem parte da estrutura física do local onde o professor trabalha, como "escola", "cadeira", "sala", "quadro", além de elementos relacionados ao material escolar, tais como "caneta" e "caderno". Essa categoria sugere a representação do professor através de elementos concretos, sendo referenciada apenas pelos As5 (em plano preferencial) e pelos As8 (em plano secundário).

A afetividade denota aspectos vinculados aos sentimentos e emoções que o termo indutor professor suscita nos alunos. Essa categoria abarca o maior número de palavras elencadas pelos As8 e As3, o que significa que esses alunos veem o professor de acordo com o sentimento que nutrem por ele (se é "chato" ou "legal", se é "bacana" ou "idiota" 
etc.). Devido à fase da adolescência em que esses alunos se encontravam, sobressaiu o seu lado analítico e crítico. O mesmo foi observado para a categoria modelo/exemplo de conhecimento ("inteligente", "sábio", "culturais"), de conduta ("responsável") e de profissional ("educador", "mestre"), de onde as palavras citadas são provenientes dos posicionamentos de As8 e As3. Os As5 não vincularam o professor a nenhum modelo de ser e estar na relação/interação com os alunos.

Pode-se entender que os alunos ao final do Ensino Fundamental ( $8^{\circ}$ ano, atual $9^{\circ}$ ano) e final do Ensino Médio ( $3^{\circ}$ ano), diferentemente daqueles do início de segundo ciclo do Ensino Fundamental (5 $5^{\mathrm{a}}$ série, atual $6^{\circ} \mathrm{ano}$ ), esperam do professor conhecimentos que propiciem a eles crescimento intelectual, humano e profissional. É o que Teixeira e Flores (2010) também mostraram em sua pesquisa com alunos do Ensino Secundário em Portugal, relatando a visão desses alunos sobre o papel da escola:

[...] a escola como local de descoberta e crescimento (intelectual e pessoal); como agente de socialização e como "rampa de lançamento" para o futuro. Para a maioria dos alunos, ela é encarada como um local onde se podem desenvolver intelectualmente, potenciando conhecimentos científicos sobre as mais variadas áreas do saber [...] (TEIXEIRA; FLORES, 2010, p. 119-120).

$O$ jeito de ser, que se refere às características e atitudes demonstradas pelo professor no exercício de sua prática ("divertido", "exigente", "brabo", "irritado", "atento", "pega no pé", etc.), foi considerado pelos As8 e As3. Os As5 novamente não relacionaram o professor a essa categoria.

Notou-se que as categorias afetividade e jeito de ser remetem-nos ao conceito de cuidado, relacionado à profissão docente. Carvalho (1999) reflete acerca do cuidado como um conceito de inúmeras significações que independem do conjunto de características femininas. No entanto, a afetividade, a proximidade nas relações interpessoais e o comportamento maternal costumam estar associados à feminização do trabalho docente. A frequente associação realizada entre o cuidado, o comportamento maternal e a feminilidade, em oposição a padrões de atuação masculinos, pode ser explicada, segundo Carvalho, pela construção social de pressupostos comuns a um ideal de mãe e de professora primária, realizada tanto na escola como fora dela.

As relações de cuidado na escola, evidenciadas pela afetividade e pelo jeito de ser do professor, estariam associadas à feminilidade e à maternidade, o que nos remete a uma concepção de infância, a um conceito de cuidado infantil e a normas sobre a adequação das mulheres a essas tarefas. Esse modelo ideal de professor seria transmitido e reproduzido no interior da própria escola, como parte da cultura escolar.

Aos aspectos pedagógicos estão vinculados os conteúdos ("matéria"), a forma ou metodologia de ensinar ("perguntas", "respostas"), as atividades ("ler", "copiar") e o processo de ensino-aprendizagem ("aprender", "ensina", "aula"). Foram os As5 quem mais projetaram no professor esses aspectos.

$\mathrm{Na}$ categoria relação/interação, entendida como a ação recíproca entre duas ou mais pessoas que ocorre no espaço escolar ("turma", "recreio", "alunos", "colegas" etc.), percebeu-se que os As3 foram os únicos que não chegaram a associar tal aspecto à figura do professor.

Ainda foram elencadas categorias como aparência ("feio" e "bonito"), avaliação ("boletim", "prova" e "nota") e autoridade ("suspensão", "disciplina" e "carrasco"), relacionadas à estética e ao poder do professor.

De acordo com a análise da associação das palavras evocadas, conclui-se que os As8 e As3 veem o professor na relação afetiva que estabelecem com ele, enquanto que os As5 percebem o professor, basicamente, na dimensão física e concreta do trabalho de ensinar ("dar aulas" e "transmitir o conhecimento"), atribuindo a ele a autoridade do saber. Esse dado pode parecer contrário ao senso comum de que os alunos de $5^{a}$ série, pela sua idade, representam o professor principalmente com base nas relações de afeto que constroem com ele. No entanto, pode-se dizer que as representações relativas ao afeto e ao conhecimento do professor coexistem no conjunto da imagem que os alunos constroem desse profissional.

\section{Representações de gênero}

A concepção de atividade docente apresenta-se de forma distinta para mulheres e homens, já que as primeiras, ao longo da história, foram consideradas como tendo dom 'natural' para o magistério, visto serem elas as responsáveis pela educação dos filhos. Com base nessa visão, a professora mulher era capaz de estender para a escola suas habilidades e saberes do trabalho doméstico e da "maternagem" (CARVALHO, 1999).

Ao serem questionados sobre a diferença entre professor homem e mulher, os As5 mostraram que projetam nesse profissional a imagem tradicionalmente construída de pais e mães. O pai como sendo austero e bravo e a mãe compreensiva, o que explica o "medo" que alguns alunos mostraram ter do professor homem, e da professora mulher maior compreensão. 
A experiência escolar de $1^{a}$ a $4^{a}$ série com professoras poderia explicar a crença inicial que certos alunos apresentaram ter sobre a competência de professores homens ("não ensinam direito"). Essa visão, no entanto, parece ser desmistificada quando os alunos cursam disciplinas com professores homens na $5^{\mathrm{a}}$ série.

M511: Várias pessoas, eu sempre tive professora mulher, nunca tive professor homem, aí várias gente [sic] diziam que os professores homens eram mais ruins [sic] de dar aula, que eles não ensinavam direito, que as mulheres tinham mais sabedoria. Mas acho que são igual [sic], eu acho que a gente aprende do mesmo jeito.

Como Ridgeway e Correl (2004) explicam, em contextos culturalmente tipificados como femininos, os homens podem sofrer algumas desvantagens; porém, quando se colocam de maneira competente e influente no contexto, acabam revertendo a sua representação.

Para os As8, tanto professores homens como mulheres são rígidos e expressam sua autoridade igualmente. Por outro lado, na entrevista com os As3, foi possível perceber, em algumas vozes, o contraste entre o modo de ser do professor homem e o da mulher, retratado em modelos machistas de sociedade. De um lado, o professor homem apresenta maior liberdade para brincadeiras e, de outro, a professora é mais comedida, paciente e controlada em seu temperamento. Quando esse controle foge às mãos da professora, sua representação é de uma mulher "estressada", distante dos padrões de delicadeza, compreensão, paciência e afetividade, demonstrando sua pouca feminilidade.

M32: As professoras são mais pacientes do que alguns professores.

M33: Ah, eu acho que não, algumas são muito estúpidas. Eu prefiro professor homem.

M32: É, eu também.

M33: É, eu acho que a mulher é muito estressada.

Esse modo de ser e agir da professora muIher parece ser a forma escolhida e exercida por ela para se impor em sala de aula. Ao fazer isso, incorpora ações ditas masculinizadas ("algumas são muito estúpidas"), gerando certo distanciamento entre ela e os estudantes. Nesse sentido, a relação entre professora mulher e alunos pode gerar conflitos. Segundo Ridgeway e Correl (2004, cf. p. 8), o impacto das crenças de gênero no comportamento é altamente responsivo à estrutura do contexto e pode variar de comportamentos imperceptíveis a comportamentos significativos. Nesse sentido, o gênero pode

\footnotetext{
${ }^{1}$ As letras M e G que aparecem na codificação dos informantes correspondem ao sexo do aluno: Menina e Garoto. O número que segue cada letra indica a série de escolarização da turma pesquisada $(5,8,3)$. O número subsequente classifica o informante da turma. A sigla $\mathbf{P q}$ corresponde à pesquisadora.
}

estar voltado para a maneira como agimos no papel de professor, sobre o que fazemos (something one does) e não sobre o que somos (something one is).

O professor homem, por sua vez, carrega uma imagem socialmente construída de autoridade e de racionalidade maior em relação ao sexo oposto. Quando assume postura de brincalhão, por acréscimo, promove um ambiente mais informal e próximo do aluno, sendo representado como alguém disposto a ser amigo e pronto para compreender os problemas dos alunos, demonstrando, assim, sinais de possível afetividade e feminilização.

\section{A idade dos professores}

Os dados mostraram que quanto mais jovem for o professor e menor a diferença de idade entre ele e os alunos, maior é a proximidade no relacionamento entre eles. Para a maioria dos alunos, professores jovens são mais "liberais", "democráticos", "criativos" e "inovadores", em comparação aos professores mais velhos, que foram vistos como "bravos", "autoritários" e conservadores. É o que ilustra o fragmento a seguir.

Pq: Um professor bem jovem, tanto faz se fosse homem ou mulher, o fato dele ou dela ser jovem traria algum problema pra vocês?

[: Não.

M51: Eu acho que não porque eu acho que é possível ela saber mais ainda, porque é jovem, mas eu acho que é a mesma coisa.

M52: Eu acho que ela vai entender melhor a gente.

Pq: E por que ela vai entender melhor?

M52: Porque assim ela já tem uma idade próxima da gente.

G52: Porque ela não viveu muito.

G51: Não, ela compreende mais a gente porque ela é mais nova, a cabeça adolescente.

Pq: Vocês se identificam mais com pessoas mais novas?

[: Jovens.

M51: Por exemplo, a de matemática, ela assim, parece ela bem jovem, a gente sempre assim /ela entende mais a gente, sabe?

G51: O professor de artes também é novo.

M51: O professor Arnaldo de Educação Física não, tem que ser do jeito que ele quer, e ele é mais veIho.

G52: Se a gente dá uma ideia ele fala "ah não, vou fazer o que eu quero agora". Mas a professora de matemática ela pode até dar, a gente dá ideia.

A idade do professor foi vista como aspecto que influencia o grau de possível relacionamento dos alunos com o professor. Nessa perspectiva, a professora mulher jovem pode ser vista como uma 
amiga ou irmã, mais do que uma mãe. Segundo Cavaco (1995), a preferência dos alunos por professores jovens permite que, em muitos casos, se estabeleçam relações próximas, quase fraternais, que contribuem para atenuar o choque com as expectativas que os alunos carregam de uma identidade profissional pré-estabelecida.

Os As8, em particular, reconheceram que professores mais velhos podem ter uma relação de "camaradagem" e de interação positiva com os alunos. Podem ter, assim dizendo, um espírito jovem.

Em linhas gerais, os dados indicaram que os alunos representam o professor jovem como aquele que pode propiciar relação mais profícua com eles. A ideia de 'ser jovem' está ligada à flexibilidade no relacionamento, à proximidade de ideias e à amizade, em oposição à rigidez e ao distanciamento de interesses vinculados à imagem de 'ser velho'. Por 'ser jovem' não implica menos conhecimento e menos autoridade, segundo a maioria dos alunos, porém traz a ideia de insegurança e inexperiência, podendo tornar a imagem do professor jovem mais vulnerável às (re)ações negativas por parte dos alunos, afetando assim sua credibilidade como profissional competente.

\section{Aparência física dos professores}

Os alunos representaram os professores por um ideário de beleza e por sua discrição e informalidade no modo de se vestirem. O desejo do belo ("bonita", "moreno", "surfista", " $1,75 \mathrm{~m}$ ", "olhos verdes", "não ser gordo") retrata uma estética enquadrada na mídia. De acordo com Boyce (1979), algumas pesquisas sugerem que o atrativo físico (physical attractness) é uma demonstração social, vista como base para uma avaliação social, um estereótipo que se constrói a partir da tese do que é bonito é bom.

As mulheres são socialmente conduzidas a tratar de si próprias como objetos estéticos e, consequentemente, a dedicar-se à beleza, à elegância do corpo, ao modo de se vestirem, à postura, sendo delegadas à gestão da imagem pública e das aparências sociais.

A atenção aos cuidados com o corpo e com a aparência física pode ser entendida como o cuidado com a respeitabilidade e ética. É o que parece entender os alunos desta pesquisa que projetaram os professores, em geral, de forma recatada, por meio de palavras como "decente", "discreta", "pudor" e "comportada". Para a maioria deles, o professor não deve chamar demais a atenção com roupas apertadas, que salientem seu corpo, ou cores muito fortes que distraiam a classe. A representação docente, nesse aspecto, pode estar vinculada ao comportamento moral intocável que se deseja à imagem do professor.

O uso de vestimentas informais é visto como elemento facilitador na relação de proximidade com os alunos. Quanto às roupas formais, como calça, camisa e sapato sociais para o professor homem, sinalizam formalidade, diferenciação e distanciamento na relação professor-alunos. Por essa maneira de se vestirem, os professores são projetados de forma estereotipada, como sérios, exigentes e rígidos. Essa projeção é contrária, se a vestimenta é informal ou casual.

Os alunos pesquisados da escola particular pareceram ser mais conservadores na projeção que fazem do professor, em comparação aos alunos de escola pública. É o caso dos As8, que julgaram estranhas e inadequadas vestimentas como bermuda, chinelo de dedo, boné e moletom, quando ligadas à imagem do professor homem. Para os As5 e As3, que já presenciaram professores de bermuda, tênis e chinelo de dedo, com certo estranhamento a princípio, acabaram se acostumando com essa imagem, pois perceberam que a competência do professor supera a sua aparência.
Pq: Chinelo de dedo sim?
M53: Ah, eu acho que não.
[: Não
G52: Às vezes é o estilo do professor.
M52: Todos vêm do jeito que eles querem, o pro- fessor também tem que vir.
Pq: Por que não de chinelo?
M53: Porque ele ia parecer mais relaxado.
G52: Ah, não tem nada a ver se viesse com os pés e as pernas bem limpinha dava.

Segundo Garcia (2002), houve uma época em que a diretora da escola controlava tudo o que acontecia no ambiente escolar, inclusive a maneira de se vestir das professoras, que não podiam usar saias muito curtas nem decotes exagerados que pudessem romper a imagem esperada de uma professora. O controle sobre a forma de se vestir ou calçar das professoras por parte da direção escolar, que pretendia ter poder sobre a moral da época e da instituição, era justificado pelo objetivo de formar moralmente as professoras e o modo de se vestir fazia parte da boa formação. Esse controle é ilustrado por Garcia (2002) que exemplifica um fato ocorrido numa escola de periferia urbana da cidade de São Paulo. Durante uma reunião pedagógica a diretora dirigiu-se a uma das professoras que era jovem, dizendo-lhe: "na minha escola uma professora não se apresenta de sandália de dedo, pois esta não é a forma correta de uma professora se calçar". (GARCIA, 2002, p. 9). 
Dentre as diversas representações de professores, é notório que, embora o controle de sua imagem não seja algo tão rígido quanto no passado, ainda há um elemento que se mantém, pelo menos para os alunos desta pesquisa: a preocupação com a manutenção de uma imagem moralmente idônea do professor.

\section{Atitude dos professores}

Independente do seu nível de escolaridade e maturidade, os alunos desta pesquisa souberam diferenciar as representações de um professor comprometido daquelas que se vinculam ao professor não comprometido. O primeiro é aquele que "ajuda", "cobra", "dá bronca", "chama a atenção dos alunos que levantam e/ou vagueiam pela sala", "tem gosto e vontade de dar aula". Contrariamente, o professor não comprometido "enrola", "não presta atenção se os alunos conversam em aula", "não tem prazer em dar aula" e "trabalha apenas por sobrevivência".

A falta de comprometimento de alguns professores também está associada aos profissionais que ficam sentados enquanto a classe realiza as atividades. Para a maioria dos alunos, essa atitude é negativa, visto que percebem que o professor deve circular pela sala para esclarecer as dúvidas, sendo esse aspecto importante para a visão de um bom professor.

A ideia de professor engajado envolve aspectos como: prazer/gosto pelo ensino, atenção dada aos alunos e domínio da matéria, que podem contribuir, segundo eles, para a disciplina de sala de aula.

A visão dos alunos sobre professor disciplinador converge para dois dos três modelos de disciplina discutidos por Lewis (2001): o modelo da Influência do professor e o modelo de Controle. No primeiro, as técnicas disciplinares baseiam-se no relacionamento, como, por exemplo, falar aos alunos sobre o impacto de um comportamento inapropriado sobre os demais colegas, confrontar justificativas irracionais e negociar a solução de problemas, considerando as necessidades do professor e as do aluno. No modelo de Controle, por outro lado, as técnicas disciplinares são baseadas na coerção, em regras claras e punições para comportamentos inapropriados.

Para os alunos deste estudo, o professor disciplinador é aquele que recorre à conversa séria, sem gritaria e violência (sem "bater na carteira"; "pegar a carteira e bater com tudo no chão"), mas eles afirmam que, algumas vezes, é necessário algum tipo de coerção ou ameaça ("É falar: pára de falar se não vou te mandar descer."); alteração na voz, pois a autoridade não se consegue na gentileza
(“Por favor, gente, não quero"); e "ser enérgico". Certas atitudes, como tirar pontos (nota) por indisciplina ou pelo esquecimento do livro ou caderno, não são consideradas técnicas punitivas adequadas para um bom disciplinador, segundo os alunos pesquisados.

Os dados ainda mostraram estreita relação entre disciplina e metodologia de ensino. Em outras palavras, o bom professor é representado como aquele que busca a atenção dos alunos através da sua forma de ensinar. Tendo o professor de Biologia como modelo, os As3 apontaram a sua maneira de agir como eficiente em sala de aula. É um professor que aproveita as falas (pertinentes ou não) dos alunos e as considera na conversa sobre a matéria. Como M33 salienta no fragmento a seguir, "ele sabe entrar na nossa". Os alunos reconheceram que essa característica não é comum no professor em geral ("ele é o exemplo de professor que se dedica aqui, pra mim ele é o que se destaca").

M33: [...] eu acho que ele [professor de Biologia] sabe dominar, ele sabe entrar na nossa, é como assim se não pode vencê-los junte-se a eles, sabe? Esse tipo de coisa. Ele não é que ele vai lá e começa a tacar papelzinho, fazer bagunça. É que ele entra, um ta conversando e ele já entra na conversa e já começa a explicar a matéria dali, então não tem como a gente desviar a atenção dele, ele sabe chamar a atenção.

M31: E é bem descontraído.

[...]

G31: Mas aí, continuando assim, na aula dele [do professor de Biologia], alguém fala alguma coisa ele pega aquilo e bota na aula e brinca.

A representação dos alunos sobre o professor, considerando sua atitude em sala de aula, é a de um profissional que respeita os alunos e se interessa por eles. Requer dos professores, portanto, cordialidade, educação, envolvimento e, quando necessário, castigo ("bota pra rua ou bota na direção").

\section{A metodologia dos professores}

$\mathrm{Na}$ sala de aula, as atitudes e a metodologia de ensinar do professor baseiam-se no que ele acredita ser eficaz para o bem-estar em sala de aula, a motivação, a atenção e a aprendizagem dos alunos. Entretanto, os dados sinalizaram um cansaço dos alunos com a metodologia utilizada pelos professores, em particular a mesmice das atividades propostas. Os alunos parecem almejar diversidade metodológica e dinamismo nas aulas (Vide XAVIER; SOUZA, 2008, que discutem essa questão na prática pedagógica do professor de língua estrangeira - Inglês). 
Observou-se que a rotina metodológica do professor parece ser um dos elementos que o caracteriza e que necessita ser repensada e transformada. Nesse sentido, a representação do bom professor está vinculada ao profissional que reflete criticamente sobre a sua prática pedagógica, com vistas a mudanças, e que se atualiza constantemente. Essa visão corrobora estudos na área da racionalidade pedagógica (THERRIEN; CARVALHO, 2009) e das abordagens reflexivas na formação de professores (GÓMEZ, 1995; SCHÖN, 1995).

Certas escolhas metodológicas podem ter repercussões na relação aluno-professor. M82, por exemplo, vincula o tipo de atividade proposta com a disciplina de sala de aula. Ou seja, "exercícios mais legais" e o "jeito de dar a aula" podem fazer a diferença no engajamento dos alunos nas aulas.

M82: O professor tem que ter domínio, você tem que controlar os alunos, não pode deixar a sala virar uma zona.

Pq: E o que o professor deve fazer?

M81: Ser mais enérgico.

M82: Fazer exercícios mais legais, o jeito de dar aula.

Para os As5, uma aula ruim é aquela que se restringe à cópia de textos do quadro, uma atividade puramente mecânica. Os dados ainda sugerem que a movimentação do professor em sala de aula enquanto explica a matéria, bem como a sua forma de explanar os conteúdos (com humor), contribuem para a qualidade das aulas.

As representações dos alunos, a partir da metodologia de ensinar dos professores, apontam para a rotina de sala de aula (a cópia de textos do quadro, o estudo da gramática, as traduções/versões), o que pode explicar a falta de interesse e motivação dos alunos. Pode ainda gerar indisciplina, agravada quando o professor ignora as vozes dos estudantes.

\section{Conclusões}

As representações dos alunos pesquisados sobre os professores sinalizam que certos elementos do ser e do fazer pedagógico podem ou não causar tensões na relação aluno-professor. A professora mulher que demonstra agir a partir de atitudes socialmente construídas como masculinas ("braba", "estressada", "estúpida") pode eventualmente provocar conflitos na relação alunos-professora, uma vez que as representações ideais conferidas a ela ("compreensiva", "paciente") são contrastadas com elementos não representativos à sua imagem tradicional. Isso não significa, necessariamente, que a professora mulher, para esses alunos, não deva exercer seu papel disciplinador.
Os As5, possivelmente pelo seu menor grau de maturidade, demonstraram marcar a divisão de gênero dos professores a partir de seus papéis tradicionalmente assumidos na família. Ou seja, o professor homem está ligado à imagem de um indivíduo sério e autoritário (o pai), enquanto que a professora mulher está associada à figura de alguém compreensiva e paciente (a mãe). Consequentemente, a figura do professor homem pode inicialmente suscitar medo aos alunos em relação à figura da professora mulher. Observou-se, no entanto, que alguns alunos conseguem assimilar como normais as trocas de papéis entre o masculino e o feminino.

Quanto à idade do professor, foi possível compreender que os alunos, em geral, identificaram os professores mais novos como possíveis companheiros. Por serem mais jovens, são vistos dentro de uma relação mais próxima e aberta com os alunos, ao contrário dos professores mais velhos, que foram projetados de forma estereotipada, como inflexíveis e distantes. A atitude jovial, contudo, foi vista como principal característica para um professor estar mais próximo dos alunos e não, necessariamente, a sua idade.

Sobre a aparência física dos professores e suas consequências na relação/interação entre alunos e professores, percebeu-se que as vestimentas e os adornos pelo corpo, tais como tatuagem ou piercing, não interferem nessa relação, muito embora algumas formas de se vestir e de se adornar dos professores possam, num primeiro momento, causar certo estranhamento aos alunos. Para eles, pareceu ser mais importante a atitude do professor, seu jeito de ensinar e o domínio da matéria do que as suas vestimentas ou aparência. Nesse sentido, a representação principal do professor é de autoridade no saber específico e em transmitir esse saber. Muito embora ele possa ser representado diferentemente pelas suas vestimentas (seja pela sua informalidade ou formalidade), nenhum conflito parece resultar desse fator.

É a atitude e a metodologia de ensinar dos professores que parecem desencadear tensões na relação/interação entre aluno e professor, como sugerem os dados. A indisciplina, a indiferença e o desinteresse dos alunos nas aulas podem ser sinais de uma possível reação contra a metodologia do professor. Da mesma forma, atitudes que sinalizam o descomprometimento desse profissional são retribuídas com a indiferença e resistência dos alunos.

Embora as percepções alimentadas pelas representações cotidianas estejam sujeitas à ruptura com a vivência e o amadurecimento do indivíduo, os dados mostraram que fatores como gênero, idade, aparência física, atitude e metodologia de ensinar dos professores influenciam de formas e níveis diferentes nas representações dos alunos sobre os professores em geral. 
Os estereótipos aplicados à representação do professor envolvem principalmente $o$ fator gênero, idade e aparência física, sendo entendidos, respectivamente, por meio de atitudes ditas masculinizadas ou feminilizadas, postura flexível (professor jovem) ou inflexível (professor não jovem) e vestimentas formais (distanciamento) ou casuais (proximidade).

No geral, a quebra da representação idealizada em relação à representação social (real) pode ou não gerar tensões em sala de aula. Quando provoca tensões, elas se caracterizam por reações como: falta de respeito do aluno para com o professor, dificuldade de o professor manter seu poder, controle e autoridade frente à turma, uso de técnicas disciplinares violentas e ameaçadoras e atitudes antipáticas de ambas as partes (aluno e professor), conforme sugerem os dados.

Por fim, os resultados deste trabalho não visam a esgotar o assunto. Constituem passo inicial para propor novos questionamentos e reflexões aprofundadas sobre as representações do professor nos aspectos aqui discutidos. Embora os contextos estudados representem uma minúscula fração da realidade, trabalhos futuros poderão especular se alunos de diferentes contextos educativos (ensino básico, universitário, escolas de idiomas), segmentos educacionais (público/privado) ou fases de escolaridade representam docentes de forma semelhante ou distinta, permitindo entender como as representações do professor se configuram na sociedade atual.

\section{Referências}

ABRIC, J. C. (Org.). Pratiques sociales et répresentaion. Paris: PUF, 1994.

BAUER, M. W; GASKELL, G. Pesquisa qualitativa com texto, imagem e som: um manual prático. Petrópolis: Vozes, 2002.

BOYCE, M. W. Physical attractiveness - a source of teacher bias? Australian Journal of Teacher Education, v. 4, n. 1, p. 1-4, 1979. Disponível em: <http://ro.ecu.edu.au/ajte/vol4/iss1/5>. Acesso em: 30 mar. 2011.

CARVALHO, M. P. de. No coração da sala de aula: gênero e trabalho docente nas séries iniciais. São Paulo: Xamã/ FAPESP, 1999.

CAVACO, M. H. Ofício do professor: o tempo e as mudanças. In: NÓVOA, A. (Org.). Profissão professor. Porto: Porto Editora, 1995. p. 155-191.

GARCIA, R. L. Um livro sobre o corpo. In: (Org.). O corpo que fala dentro e fora da escola. Rio de Janeiro: DP\&A, 2002. p. 7-16.
GILLY, M. As representações sociais no campo educativo. Educar em Revista, Curitiba, n. 19, p. 231-252, 2002.

GÓMEZ, A. P. O pensamento prático do professor - A formação do professor como profissional reflexivo. In: NÓVOA, A. (Ed.). Os professores e a sua formação. 2. ed. Lisboa: Publicações Dom Quixote - Instituto de Inovação Educacional e autores, 1995. p. 95-114.

GUARESCHI, P. A.; JOVCHELOVITCH, S. (Orgs.). Textos em representações sociais. Petrópolis. Rio de Janeiro: Vozes, 2002.

JOBIM E SOUZA, S. Os paradoxos da imagem e a experiência com o conhecimento e a cultura. In:

(Org.). Mosaico: imagens do conhecimento. Rio de Janeiro: Rios Ambiciosos, 2000. p. 15-22.

LEWIS, R. Classroom discipline and student responsibility: the students' view. Teaching and Teacher Education, n. 17, p. 307-319, 2001.

MAYA, M. A autoridade do Professor. Lisboa: Texto Editora, 2000.

MENIN, M. S. de S.; SHIMIZU, A. de M. (Org.). Experiência e representação social: questões teóricas e metodológicas. São Paulo: Casa do Psicólogo, 2005.

$\mathrm{MOSCOVICI}, \mathrm{S}$. As representações sociais da psicanálise. Rio de Janeiro: Jorge Zahar, 1978.

A representação social da psicanálise. Rio de Janeiro: Zahar Editores, 1981.

Psycologie sociale. Paris: PUF, 1984.

2004.

Representações sociais. Petrópolis: Vozes,

MOSCOVICI, S; HEWSTONE, M. De la ciencia al sentido comum. In:_ (Org.). Psicologia social 2. Barcelona: Paidós, 1983. p. 679-710.

OLIVEIRA, F. O; WERBA, G. C. Representações Sociais. In: JACQUES, M. G. C. (Org.). Psicologia social contemporânea. Petrópolis-RJ: Vozes, 2002. p. 104117.

RIDGEWAY, C. L.; CORREL, S. J. Unpacking the gender system: a theoretical perspective on gender beliefs and social relations, Gender \& Society, v. 18, n. 4, p. 510-531, 2004.

SCHÖN, D. A. Formar Professores como profissionais reflexivos. In: NÓVOA, A. (Ed.). Os professores e a sua formação. 2. ed. Lisboa: Publicações Dom Quixote - Instituto de Inovação Educacional e autores, 1995. p. 79-91.

TEIXEIRA, C.; FLORES, M. A. Experiências escolares de alunos do ensino secundário: resultados de um estudo em curso. Revista Educação e Sociedade, Campinas, v. 31, n. 110, p. 113-133, jan./mar. 2010. DOI: 10.1590/S0101-73302010000100007 
THERRIEN, J.; CARVALHO, A. D. F. O professor no trabalho: epistemologia da prática e ação/ cognição situada - elementos para a análise da práxis pedagógica. Revista Brasileira de Formação de Professores - RBFP, Cristalina, v. 1, n. 1, p. 129-147, maio, 2009.

XAVIER, R. P.; SOUZA, D. T. O que os alunos pensam sobre o livro didático de inglês? Trabalhos em Linguística Aplicada, Campinas, v. 47, n. 1, p. 65-89, jan./ jun. 2008. DOI: 10.1590/S0103-18132008000100005

Recebido em 15/04/2011

Versão final recebida em 29/08/2011

Aceito em 31/08/2011 